\title{
Real time B-Scan evaluation of Posterior chamber \& extraocular pathologies of Eye \& Orbit
}

\author{
Netam SBS ${ }^{1}$, Jain $\mathbf{V}^{2}$, Singh $\mathbf{R}^{3}$, Sanjay Kumar ${ }^{4}$, Dutt $\mathbf{V}^{\mathbf{5}}$ \\ ${ }^{1}$ Dr. Satya Bhuwan Singh Netam, Associate Professor, Pt JNM Medical College Raipur, CG, India, ${ }^{2}$ Dr. Vishal Jain, \\ Assistant Professor, Pt JNM Medical College Raipur, CG, India, ${ }^{3}$ Dr. Rajesh Singh, Assistant Professor, Pt JNM Medical \\ College Raipur, CG, India, ${ }^{4}$ Dr. Sanjay Kumar, Associate professor, Pt JNM Medical College, Raipur, CG, India, \\ ${ }^{5}$ Dr. Vishnu Dutt, Professor/Dean, CIMS bilashpur, Chhattishgarh, India.
}

Address for Correspondence: Dr. Satya Bhuwan Singh Netam, Associate Professor, D-20, Avani Vihar, Daldalseoni Road Mova, Raipur, Chhattishgarh, India. Email: sbsnetam@yahoo.com

\begin{abstract}
Objective: Aim of this study is to assess the usefulness and accuracy of high frequency real time ultrasound using non dedicated all purpose scanner to detect and characterise posterior chamber and extraocular pathologies in trauma and non-traumatic eye and to establish etiology of proptosis. Material \& Method: A total number of 138 cases (145 eyes) were included in the study. Ultrasound evaluation of eyes with diagnosed or suspected posterior segment pathology, cases of trauma, suspected or diagnosed intraocular tumors / extraocular pathologies and cases presenting with proptosis. Patients lost to follow up and eyes with normal scan were excluded. Supplementary investigation (CT, MRI) done where ever needed. The findings of B-scan then correlated with the ophthalmoscopic/ surgical findings/histology/follow up after treatment. Results: Distinction between intra and extra-ocular pathologies was 100\%. The commonest posterior segment pathology in non traumatic eyes was retinal detachment and in traumatic eye was vitreous haemorrhage with diagnostic accuracy of $98.9 \%$ and $97.9 \%$ respectively. Retinoblastoma and pseudotumor (15\%) were the commonest intra and extraocular mass lesions respectively. Accuracy in localization of foreign bodies and dislocated lens, in diagnosing retinoblastoma, in diagnosis and characterization of thyroid orbitopathy, cavernous hemangioma, tumors, cellulitis, dermoids, cysticercosis and intraorbital cysts was excellent. "Triple wall” sign is typical for intraorbital hydatid cyst. Conclusion: B-mode real time ultrasound using non-dedicated all purpose high frequency transducer provides nonionizing, cost effective, non-invasive technique with excellent image quality and high accuracy for diagnosis and assessment of posterior segment and extraocular pathologies.
\end{abstract}

Keywords: B-scan, Eye, Orbit, Ultrasound.

\section{Introduction}

Starting with abdominal and obstetric application, ultrasound has made an impact on virtually every area of human body. The first application of ultrasound in ophthalmology using one dimensional A-scan was done by Mundt and Hughes in 1956 [1]. The B-scan (Brightness modulation scan) was first introduced by Baum and Greenwood in 1958 [2]. In opaque ocular media there is no mean of assessment of posterior segment of eye ball [3]. As technology improvised, it become apparent that high frequency ultrasound is an excellent tool to take a peep in the dark world behind the opaque media which precluded all optical

Manuscript received: $20^{\text {th }}$ Aug 2015

Reviewed: $30^{\text {th }}$ Aug 2015

Author Corrected: $14^{\text {th }}$ Sept 2015

Accepted for Publication: $21^{\text {th }}$ Sept 2015

International Journal of Medical Research and Review techniques. Being a pilot study in our region we included all cases of posterior segment and extraocular pathologies in our study. Here we presenting few uncommon pathologies along with common pathologies and there B-scan appearances in our study.

\section{Material \& Method}

This study was a prospective, observational and descriptive study conducted at Pt. J.N.M. medical College and Hospital, Raipur (C.G.). A total number of 138 cases (145 eyes) were included in the study. Aloka Prosound (SSD4000) Colour Doppler machine with a $7.5 \mathrm{MHz}$ linear transduser was used. Contact technique was used for scanning. All the measurements were done 
by the use of electronic callipers. Supplementary investigation (CT, MRI) done where ever needed. Eyes with diagnosed or suspected posterior segment pathology with opaque or clear media, cases of trauma, suspected or diagnosed intraocular tumors, suspected or diagnosed extraocular pathologies and cases presenting with proptosis were included in the study while patients lost to follow up and eyes with normal scan were excluded. Findings of B-scan were correlated with the ophthalmoscopic /surgical findings, histology or follow up after medical or surgical treatment.

Incidence (in percentage) of various posterior chamber and extraocular pathologies and sensitivity, specificity and accuracy of real time ultrasound in their diagnosis was calculated using standard formulae.

\section{Observation}

Total 145 eyes (138 patients) included in the study were divided into 4 groups (Table No I).

Table I - Distribution of eyes in the study

\begin{tabular}{|c|c|c|c|}
\hline $\begin{array}{c}\text { S. } \\
\text { No. }\end{array}$ & Group & No. of Eyes & Percentage (\%) \\
\hline 1 & Non trauma non tumor posterior segment pathology & 62 & 44 \\
\hline 2 & Trauma & 35 & 24 \\
\hline 3 & Suspected intraocular tumor & 14 & 9 \\
\hline 4 & Suspected extraocular pathologies & 34 & 23 \\
\hline & Total & $\mathbf{1 4 5}$ & $\mathbf{1 0 0}$ \\
\hline
\end{tabular}

We found 85 posterior segment pathologies in non tumor non trauma group (Table-No-II). In this group commonest pathology noted was retinal detachment $26(30.5 \%)$, followed by vitreous haemorrhage $19(22.3 \%)$, Vitreous membrane $6(7 \%)$, Increased axial length of eye ball 8(9\%), Asteroid hyalosis 4(4.7\%), Choroidal detachment 5(5.8\%) and 17(20\%) miscellaneous lesions. Intra ocular cysticercosis is the most infrequently found lesion in miscellaneous lesions. Two cases of intraocular cysticercosis are subretinal in location associated with total retinal detachment.

Table II - Distribution of posterior segment pathologies (non tumor non trauma group)

\begin{tabular}{|l|c|c|c|}
\hline S.No & Lesion & Number of cases & \% \\
\hline 1. & Total retinal detachment & 26 & 30.5 \\
\hline 2. & Vitreous haemorrhage & 19 & 22.3 \\
\hline 3. & Vitreous opacities/membrane & 6 & 7 \\
\hline 4. & Increased axial length of eye ball & 4 & 4.4 \\
\hline 5. & Asteroid hyalosis & 5 & 5.8 \\
\hline 6. & Choroidal detachment & 17 & 20 \\
\hline 7. & Miscellaneous lesions & $\mathbf{8 5}$ & $\mathbf{1 0 0}$ \\
\hline
\end{tabular}

Miscellaneous lesions includes : retinal cyst-2, Papilloedema-2, posterior vitreous detachment-3, posterior staphylome-2, optic neuritis-2, drusen-1, displaced IOL-2, endopthalmitis-1, Intraocular cysticercosis-2.

We found 62 posterior segment pathologies in blunt \& penetrating trauma cases (Table No-III). There is considerable overlap between the pathologies with blunt and penetrating trauma. However dislocation of lens and edematous retinochoroid was seen only in blunt trauma whereas intraocular foreign body and endopthalmitis was seen in penetrating trauma. The commonest pathology in trauma was vitreous haemorrhage ( 23 eyes), followed by retinal detachment ( 12 eyes). 
Table III - distribution of lesions in traumatic group

\begin{tabular}{|c|c|c|c|}
\hline S. No & Lesion & No. of lesions & \% \\
\hline 1. & Vitreous haemorrhage & 23 & 37 \\
\hline 2. & Total retinal detachment & 12 & 6.4 \\
\hline 3. & Traumatic cataract & 04 & 6.4 \\
\hline 4. & Choroidal detachment & 04 & 6.4 \\
\hline 5. & Intraocular foreigh body & 04 & 24.1 \\
\hline 6. & Miscellaneous lesions & 15 & $\mathbf{1 0 0}$ \\
\hline
\end{tabular}

Miscellaneous lesions include: Hyphema-3, Retinal dialysis-2,posterior displacement of lens-3,Lens in anterior chamber1, Retino-choroidal edema-2, Carotico-cavernous fistula-1, Intraoccular foreign body-1, Endopthalmitis-2.

We found 14 cases of Retinoblastoma, out of which 11 were endophytic type and others were exophytic, recurrent and retinoblastoma with retinal detachment. Calcification is seen in all except in recurrent type. Most common extra ocular pathology (Table IV) noted is pseudotumor in 5 eyes (4 patients) followed by dermoid cyst in 4 eyes. Diagnosis on Bscan was confirmatory in cases of thyroid orbitopathy, cavernous haemangioma, optic nerve sheath meningioma, cellulites (abscess), dermoid, conjunctival cyst and cysticercosis. In other pathologies mentioned in table VI, diagnosis on B-scan was doubtful, correlated and confirmed by other investigation (histology, CT, MRI) and follow up (cases of pseudotumors responded to steroid). Metastases (3 eyes) are diagnosed as case of AML which is bilateral in one and unilateral in another. Two case of cysticercosis were found in MR muscle and one in lacrimal gland region. All 3 cases show characteristic pattern on B-scan and completely resolved after treatment with albendazole.

Table IV- shows distribution of eyes with Extraocular pathologies

\begin{tabular}{|c|c|c|}
\hline S. No & Lesion & No. of cases. \\
\hline 1. & Pseudotumor & 05 \\
\hline 2. & Thyroid orbitopathy & 03 \\
\hline 3. & Metastasis & 03 \\
\hline 4. & Dermoid & 04 \\
\hline 5. & Cysticercosis & 16 \\
\hline 6. & Miscellaneous lesions & 34 \\
\hline
\end{tabular}

Miscellaneous lesions include: Rhabdomyosarcoma-1, Cavernous hemangioma-1, ON sheath meningioma-1, Solitary neurofibroma-1, Plexiform neurofibroma-1, Lid haemangioma (capillary)-2, Lid carcinoma-2, Lacrimal gland tumor-1, Cellulitis (phlegmon)/abscess-2, Conjunctival cyst-1, Intraorbital Hydatid cyst-2, Fibrous dysplasia-1

Most common cause of proptosis (Table V) was macrophthalmos (increased axial length of eye ball) also known as pseudoproptosis (25\%), followed by pseudotumors (15\%) and metastasis. Other causes of proptosis were thyroid orbitopathy and parasitic infection, Metastasis from leukaemia, pseudotumor in the form of bilateral dacryoadenitis with lid masses, plexiform neurofibroma, carotico- cavernous fistula, dermoid, hydatid cyst, fibrous dysplasia, Intraorbital abscess, Optic nerve neurofibroma, cavernous haemangioma and Rhabdomyosarcoma.

Table V-Shows distribution of diseases causing proptosis

\begin{tabular}{|c|c|c|c|}
\hline S. No. & Disease & No. of Cases & \% \\
\hline 1 & Pseudoproptosis (increased axial length) & 08 & 25 \\
\hline 2 & Pseudotumor. & 05 & 15 \\
\hline 3 & Metastatic tumor & 03 & 09 \\
\hline 4 & Thyroid orbitopathy & 03 & 09 \\
\hline 5 & Extraocular cysticercosis & 03 & 09 \\
\hline 6 & Miscellaneous lesions & 11 & 33 \\
\hline & Total & $\mathbf{3 3}$ & $\mathbf{1 0 0}$ \\
\hline
\end{tabular}


Miscellaneous lesions : Neurofibroma (P)-1, Dermoid-2, Cavernous hemangioma-1, Lacrimal gland tumor-1, Rhabdomyosarcoma-1, Fibrous dysplasia-1, Carotico-cavernous fistula-1, Intraorbital hydatid cyst-2. Intraorbital abscess-1.

\section{Discussion}

In this study, we included 138 patients (145 eyes) classified in four general categories - non trauma non tumor posterior segment pathologies, trauma, intraocular tumor and extraocular pathologies. Coleman DJ[4] classified the patients into 5 general categories for their ocular problem - retinal detachment, vitreous haemorrhage, intraocular tumor, trauma and foreign body, miscellaneous condition i.e. choroidal detachment.

Retinal detachment-Complete retinal detachment was seen as V/Y or $\mathrm{T}$ (closed funnel) shaped (fig 1a, 1b) uniformly reflective echogenic membrane extending from the ora serrata to the optic disc. Fresh detachment shows moderate after movement and old detachment shows restricted after movement. Tractional retinal detachment (fig-1d) seen as echogenic tent like membranes with a vitreous membrane attaching to its apex and shows restricted after movements on kinetic imaging. It usually occurs in eyes with vitreous membranes attached to the retinal surface. These ultrasound features are corroborative with findings described by Coleman DJ [4,5,6], Sutherland et al [7], Vashisht and Berry [8], and Ahmed et al [9]. In our study, retinal detachment in non trauma non tumor and trauma group showed overall incidence of $27.03 \%$, sensitivity $100 \%$, specificity $98.24 \%$ and diagnostic accuracy of $98.9 \%$. Similar results were observed by OP Sharma [10], Coleman DJ [4] and Sen et al [11]. One falsely diagnosed case of tractional retinal detachment was found in non trauma non tumor group which was turn out to be thick vitreous band due to chronic vitreous haemorrhage. A similar difficulty was also reported by Mc Nicholas et al [12], Azzolini et al [13] and Mc Quown [14].
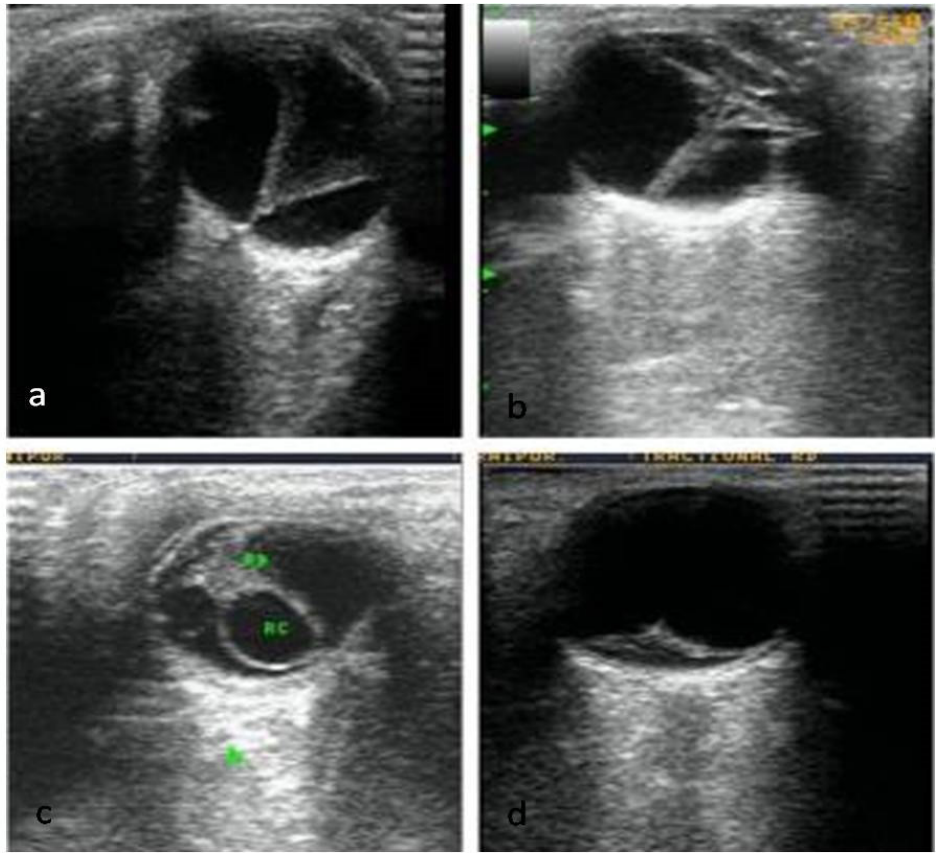

Figure 1: Complete retinal detachment a) open b) closed c) retinal cyst d) tractional

Vitreous haemorrhage, vitreous membranes and posterior vitreous detachments: Fresh vitreous haemorrhage appeared as low to medium level echoes in the vitreous and old vitreous haemorrhage was seen in the form of free floating membranes or the membrane attachment to the retinal surface. Posterior vitreous detachment was seen as thin low reflective membranes which show considerable after movements on kinetic imaging. These findings were similar to those described by Coleman et al [5,6], Vashisht and Berry [8], OP Sharma [10], Bedi et al [15] and Aironi et al [16]. Our study shows sensitivity, specificity and accuracy of $97.9 \%$ in diagnosing vitreous haemorrhage. Result was similar to the study by OP Sharma [10]. 1 case of vitreous haemorrhage was falsely diagnosed as tractional retinal detachment and 1 case was diagnosed as vitreous haemorrhage which were turn out to be endopthalmitis on follow up. 
Choroidal detachment: On B-scan Choroidal detachment was presenting as uniformly thick biconvex membrane located peripherally, not attached to the optic disc and show no after movement on kinetic imaging. The subchoroidal space was clear in serous detachment while extensive bullous (hemorrhagic) choroidal detachment shows thick echoes in subchoroidal space. The bullous (hemorrhagic) choroidal detachment was associated with history of malignant hypertension and was confusing with large choroidal melanoma. Similar findings were described by Kwong et al [17], Mc Nicholas et al [13], Chugh et al [18], O P Sharma [10], Puodziuviene et al [19]. It was correctly diagnosed by B scan ultrasound in all cases in present study. Similar results were obtained by Kwong et al [17] and Chugh et al [18].

Asteroid hyalosis: Asteroid hyalosis were seen as multiple high amplitude dots like echoes in the vitreous, which showed considerable after movements on kinetic scanning. There was a clear space between the echoes and the retina. We found 4 eyes with asteroid hyalosis, all in elder age group ( $>60 \mathrm{yrs})$. Similar findings were described by Bronson NR [20], O P Sharma [10], Bedi et al[15].

Optic nerve drusen, Papilloedema and optic neuritis -: On the B scan ultrasound drusen seen as elevation at optic nerve with calcification. Papilloedema was seen as elevation of the optic disc whereas optic neuritis was seen as thickening of the optic nerve in addition to the elevated disc. Findings are similar to that described by Bronson NR [20].

Endopthalmitis: Endopthalnitis appeared as intermediate level free mobile internal echoes and membranes associated with thickening of the ocular coat $(>3 \mathrm{~mm})$. Similar findings were also described by Berrocal et al [21], Dacey MP et al [22] and Puodziuviene et al [19].

Trauma: Vitreous haemorrhage was the commonest finding in trauma cases $(43.3 \%)$ followed by retinal detachment (26.4\%). Other findings include choroidal detachment (7.5\%), dislocated lens (7.5\%), intraocular foreign bodies $(7.5 \%)$ and endopthalmitis. Similar findings were described by Kwong et al [17], OP Sharma [10] and Aironi et al [16]. Foreign bodies were seen as small bright areas with marked posterior reverberation artefacts posteriorly. Similar findings were described by Vashisht and Berry [8], McNicholas et al [13] and Chugh et al [18]. Carotid-cavernous fistula (fig. 2) was presenting with lid swelling and proptosis having history of blunt trauma 1 month back. B-scan shows engorged dilated superior ophthalmic vein with reverse pulsatile flow on color doppler and multiple small dilated channels in retrobulbar space. Contrast CT scan shows similar findings along with dilated ipsilateral cavernous sinus. Similar findings were described by Duan et al [23], Belden et al [24] and Lieb et al [25].
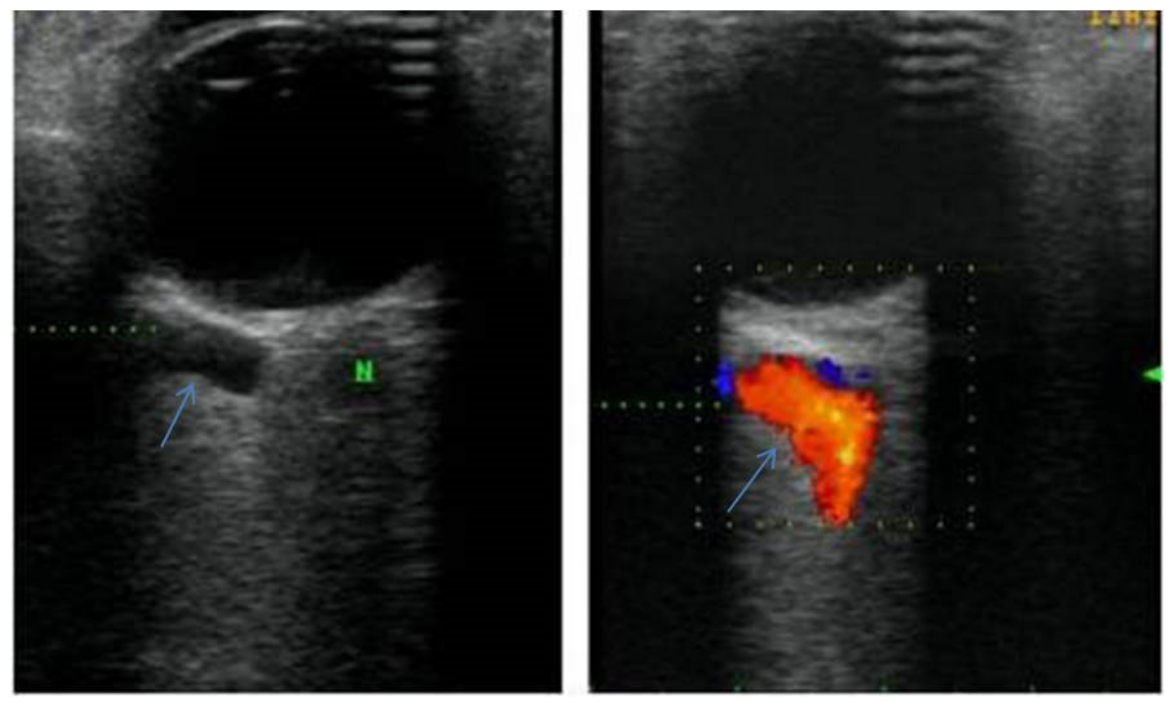

Figure 2: Carotid cavernous fistula - dilated superior ophthalmic vein in retroblbar space showing reversal of blood flow on doppler (arrow).

Cysticercoids -: Both intra \& extraocular cysticercosis on ultrasound show subcentimeter size cyst with eccentric echogenic scolex. 2 cases of intraocular cysticercosis were subretinal in location and associated with retinal detachment. 
Out of 3 cases, 2 extraocular cysticercosis were found in medial rectus muscle and 1 was found in the region of lacrimal gland. In the study by Kaliaperumal et al [26] and Madigubba et al [27] they showed intraocular cysticercosis to be more common then orbital involvement. Subretinal cysticercosis showed less response to albendazole then extraocular cysticercosis which showed good response and resolved completely. Similar findings were mentioned by Prasad et al [28], Lombardo J [29] and Das et al [30].

Pseudotumors (idiopathic orbital inflammation) were seen as diffuse ill-defined homogenously hypoechoic masses. These three cases ( 1 bilateral and 1 unilateral) were diagnosed as dacryoadenitis. One of them shows extensive involvement of extraconal muscle involvement (fig.3a,b). CECT orbit showed soft tissue density enhancing masses involving lid, lacrimal gland and retro bulbar space (fig. 3d). There was prompt response to corticosteroid (fig. 3e) which confirmed the diagnosis. Similar findings were described by Mc Quown [14], OP Sharma [10] and Chaudhary et al [31].
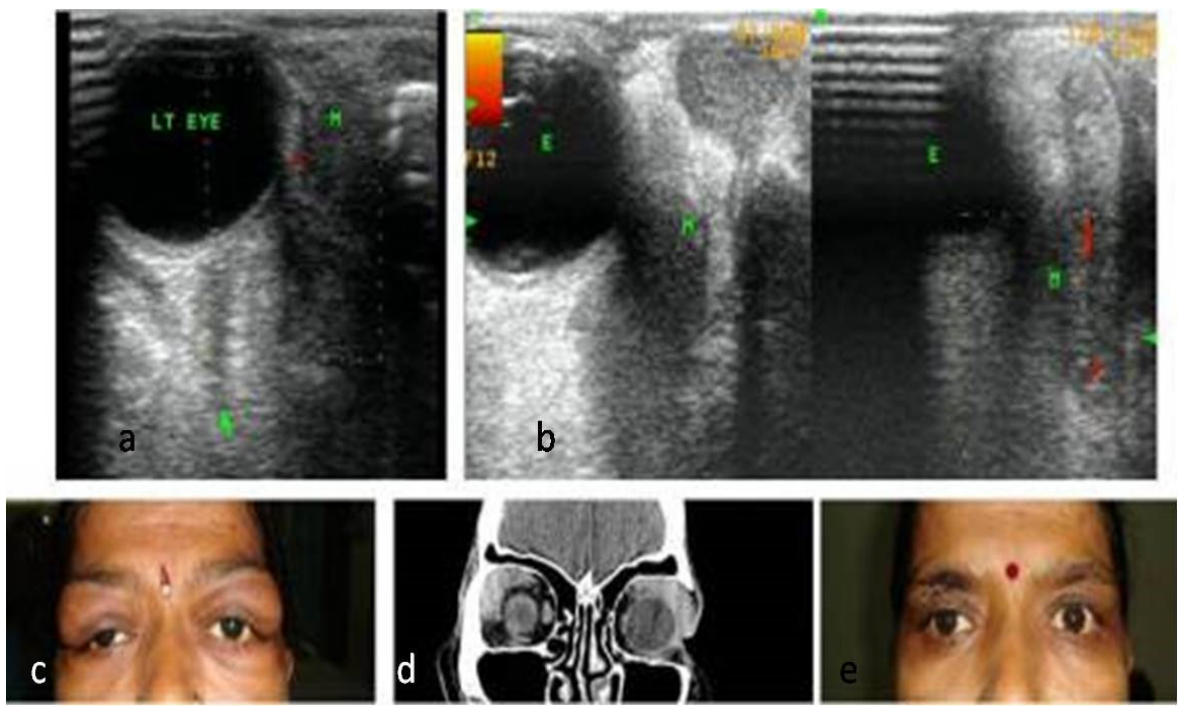

Figure 3: Orbital pseudotumor - Diffusely infiltrative extraocular mass (M) with both intra- \& extraorbital extension $(a, b)$ showing vascularity in doppler. Fig. (c) Shows patients with b/l lid swelling, coronal CT image (d) shows homogenous enhancing masses in b/l superotemporal region. Complete resolution (e) after treatment with steroid.

Capillary hemangioma was found in 2 cases, presented with lid mass. Both the patients were <5yrs of age. They showed ill defined irregular masses of high internal echo reflectivity with foci of calcification and vascularity on doppler. Similar findings were described by Berrocal et al [18] and OP Sharma [7]. One 35 yrs old female presented with proptosis, on B scan showed a well defined homogenously hypoechoic intraconal mass with no detectable color flow on Doppler, diagnosed as cavernous hemangioma. Lieb WE [25] stated that in cavernous hemangioma stagnant/slow blood flow is below detection level and no flow seen on color doppler as it was in our case.

Thyroid orbitopathy was found in 3 patients as bilateral eye involvement. There was asymmetrical involvement with medial rectus being most commonly involved muscle. All patients have raised thyroid status. Similar findings were described by McQuown [14], Dubey et al [32] and OP Sharma [10].

Dermoid cyst was found in 4 patients. 2 patients presented with lid mass at superolateral margin, one in superior orbital space and one in lacrimal gland region. On ultrasound they showed cystic lesion with homogenous low level internal echoes. CT scan showed fat attenuation in cystic lesion confirming the diagnosis.

Conjunctival cyst showed well defined anechoic cyst anterior to the eye ball showing movement with the globe on dynamic scan.

We found one case of optic nerve meningioma which showed hypoechoic mass encasing the optic nerve. It was confirmed by CT scan and histopathology correlation. Similar finding was described by OP Sharma et al [10]. 
We found two cases of orbital metastasis in our study which were below 10yrs of age and were known case of myeloid leukaemia. It was bilateral in one case and unilateral in other. In 2 eyes it was extraconal while in one it has diffuse involvement. On ultrasound it shows homogenously low internal reflectivity in all 3 eyes. All previous reports shows neuroblastoma to be the most common orbital metastasis in children. Dubey et al [32] stated that in children orbit is more frequently involved then globe. Bianciotto et al [33] showed melanoma as the most common primary for orbital metastasis.

One case of plexiform neurofibroma was seen as soft tissue mass over the eyelid with intraorbital extraconal extension through superolateral margin. One case of solitary neurofibroma presents as lid mass with no intraorbital extension. One case of rhabdomyosacoma was seen as an extraconal hypoechoic mass with high vascularity on doppler. One Case of intraorbital abscess showed rounded hypoechoic area with peripheral vascularity. Similar findings for the lesions described above are also mentioned by McQuown [14] and OP Sharma [10].

Two cases of intraorbital hydatid cysts in our study shows unilocular cyst with well defined "triple layer" wall. CT scan and MRI shows cyst with well defined wall (fig. 4). Betharia et al [34] described a diagnostic "double wall" sign for intraorbital hydatid on ultrasound.
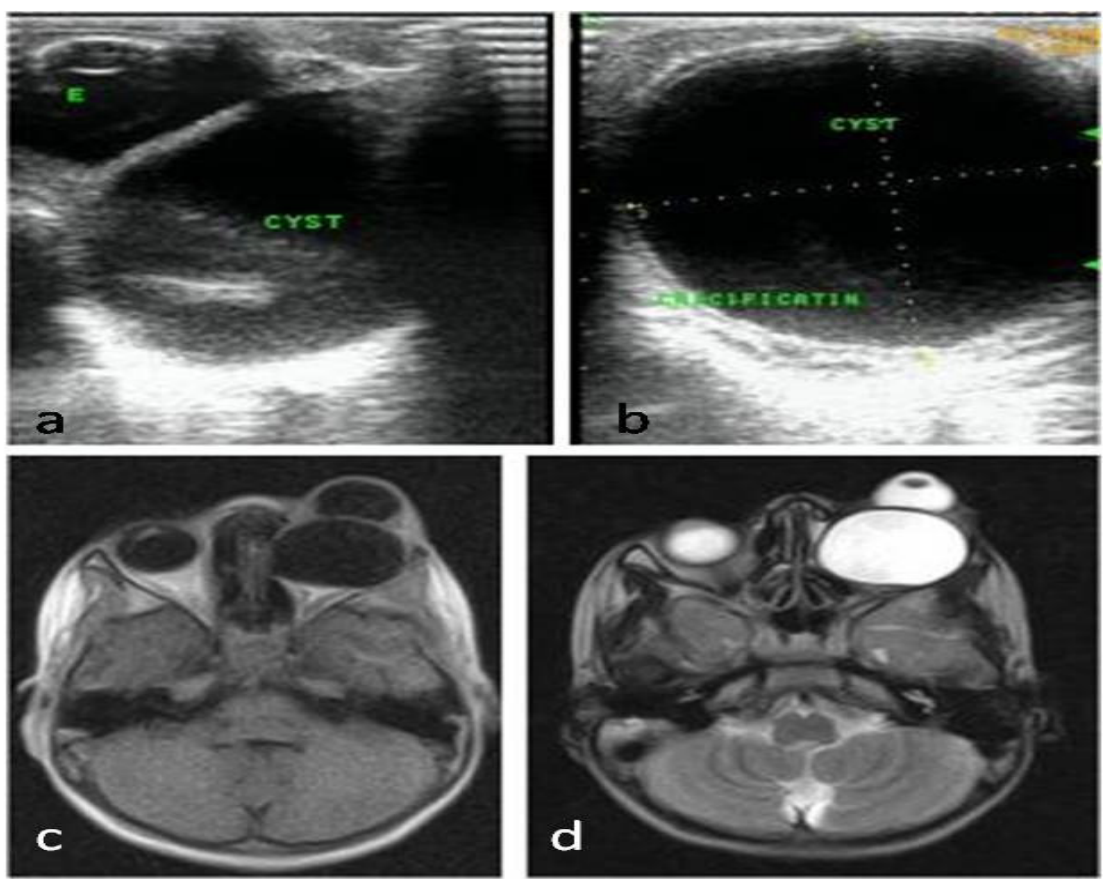

Figure 4: Hydatid cyst - well defined unilocular thick wall cystic lesion in retro-ocular space (a) with "triple wall sign"(b) and correlative axial T1 (c) and T2WI (d)

One case of fibrous dysplasia of sinus origin in 10yr old male presented with eccentric proptosis. On Ultrasound there was no obvious finding except Protrusion of eye ball, on CT scan there was diffuse expansion of maxilla with ground glass density with central cystic degeneration. Diagnosis confirmed on histopathology.

Summary and conclusion: Real time B scan ultrasound proved to be essential for screening of all eyes with opaque media with suspected posterior segment abnormalities. Ultrasound is easy, quick, non-invasive, non-hazardous, well tolerated, bed side procedure done with no prior patient preparation. Satisfactory evaluation of both intraocular and extraocular pathologies was done by using non-dedicated all purpose high frequency transducer, which is widely available in most radiology departments.

Distinction between intraocular and extraocular pathologies was made in $100 \%$ of the cases. B-scan is highly accurate in diagnosing posterior chamber pathologies. Diagnostic difficulty only arise in eyes with multiple pathologies, dense 
membranes and focal retinal detachments, especially in differentiating focal retinal detachments from dense echogenic preretinal vitreous membranes. However, thorough scanning in all planes and attachment sites should be carefully looked to reduce the diagnostic errors. Ultrasound helps in localizing the foreign bodies and dislocated lens accurately. Ultrasound was $100 \%$ accurate in diagnosing retinoblastoma however all eye with retinoblastoma should undergo CT scan to know exact extent and intracranial extension. Although CT scan is essential for studying extraocular pathologies, the tissue characteristics are better resolved by ultrasound and vascularity can be assessed by doppler.

Ultrasound has a complementary role to CT in the evaluation of eyes with proptosis. B-scan ultrasound shows $100 \%$ accuracy in diagnosis and characterization of cases of thyroid orbitopathy, cavernous hemangioma, optic nerve sheath tumor, cellulites (abscess), dermoid, conjunctival cyst, cysticercosis and intraorbital cysts.

We described typical "Triple wall" sign for diagnosing intraorbital hydatid cyst to differentiate it from other intraorbital cystic masses. We found ultrasound as the most reliable modality for assessment of therapeutic response in ocular and orbital cysticercosis. Ultrasound has limited role in assessing extra-orbital extension and bony pathologies.

In conclusion, B-mode real time ultrasound using non-dedicated all purpose high frequency transducer provides nonionizing, cost effective, non-invasive technique with excellent image quality for diagnosis and assessment of posterior segment and extraocular pathologies.

\section{References}

1. Mundt.G and hughes W. Ultrasound in ocular diagnosis. Am J Ophthalmol, 1956; 41:488198.

2. BAUM G, GREENWOOD I. The application of ultrasonics locating techniques to ophthalmology; theoretic considerations and acoustic properties of ocular media. I. Reflective properties. Am J Ophthalmol. 1958 Nov;46(5 Pt 2):319-29.

3. Coleman JD. Ultrasonography of eye and orbit. 2nd ed. Lippincott: Williams and Wilkins; pp. 47-122.

4. Coleman DJ. Reliability of ocular and orbital diagnosis with B-scan ultrasound. American journal of ophthalmology 1972 April; 73(4):501-16.

5. Jack RL, Coleman DJ. Detection of retinal detachments secondary to choroidal melanoma with Bscan ultrasound. Am J Ophthalmol. 1972 Dec;74 (6): 1057-65.

6. Coleman DJ, Jack RL, Franzen LA. Ultrasonography in ocular trauma. Am J Ophthalmol. 1973 Feb;75 (2): $279-88$.

7. Sutherland GR, Forrester JV, Railton R. Echography in the diagnosis and management of retinal detachment. Br J Radiol. 1975 Oct;48(574):796-800.

8. Vashisht S, Berry M. Ultrasound evaluation of the eye. Indian journal of radiology \& imaging 1994; 4: 195-201.
9. Ahmed J, Shaikh FF, Rizwan A, Memon MF. Evaluation of vitreo retinal pathologies using B-scan ultrasound. Pak J Ophthalmol 2009; 25(4).

10. O.P.Sharma. Orbital sonography with its clinicsurgical correlation. Ind J Radiol Imag 2005; 15(4): $537-554$.

11. Lt Col KK Sen, Lt Col JKS Parihar, Maj M Saini, Brig RS Moorthy. Conventional B-mode ultrasonography for evaluation of retinal disorders. Medical Journal Armed Forces India 2003; 59: 310-312

12. Azzolini C, Pierro L, Candino M, Brancato R. Reliability of preoperative ultrasonography evaluation for vitreoretinal surgery. Eur J Ophthalmol. 1994 AprJun;4(2):82-90.

13. McNicholas MM, Brophy DP, Power WJ, Griffin JF. Ocular sonography. AJR Am J Roentgenol. 1994 Oct;163(4):921-6.

14. McQuown DS. Ocular and orbital echography. Radiol Clin North Am. 1975 Dec;13(3):523-41.

15. Bedi DG, Gombos DS, Ng CS, Singh S. Sonography of the eye. AJR Am J Roentgenol. 2006 Oct;187(4):1061-72.

16. Aironi VD, Gandage SG. Pictorial essay: B-scan ultrasonography in ocular abnormalities. Indian $\mathrm{J}$ Radiol Imaging. 2009 Apr-Jun;19(2):109-15. doi: 10.4103/ 0971-3026.50827. 
17. Kwong JS, Munk PL, Lin DT, Vellet AD, Levin M, Buckley AR. Real-time sonography in ocular trauma. AJR Am J Roentgenol. 1992 Jan;158(1):179-82.

18. Chugh JP, Susheel, Verma M. Role of ultrasound in ocular trauma. Ind J Radiol Imag 2001; 11(2):75-79.

19. Puodziuvien E, Paunksnis A, Kurapkien S, Imbrasien D. Ultrasound value in diagnosis, management and prognosis of severe eye injuries. ISSN 1392-2114 ULTRAGARSAS, Nr. 3(56).2005.

20. Bronson NR 2nd. Contact B-scan ultrasonography. Am J Ophthalmol. 1974 Feb;77(2):181-91.

21. Berrocal T, de Orbe A, Prieto C, al-Assir I, Izquierdo C, Pastor I, Abelairas J. US and color Doppler imaging of ocular and orbital disease in the pediatric age group. Radiographics. 1996 Mar; 16(2):2 51-72.

22. Dacey MP, Valencia M, Lee MB, Dugel PU, Ober RR, Green RL, Lopez PF. Echographic findings in infectious endophthalmitis. Arch Ophthalmol. 1994 Oct; 112(10):1325-33.

23. Duan Y, Liu X, Zhou X, Cao T, Ruan L, Zhao Y. Diagnosis and follow-up study of carotid cavernous fistulas with color Doppler ultrasonography: analysis of 33 cases. J Ultrasound Med. 2005 Jun;24(6):739-45.

24. Belden CJ, Abbitt PL, Beadles KA. Color Doppler US of the orbit. Radiographics. 1995 May;15(3): 589-608.

25. Lieb WE. Color Doppler ultrasonography of the eye and orbit. Curr Opin Ophthalmol. 1993 Jun;4(3):68-75.
26. Kaliaperumal S, Rao VA, Parija SC. Cysticercosis of the eye in South India--a case series. Indian J Med Microbiol. 2005 Oct;23(4):227-30.

27. Madigubba S, Vishwanath K, Reddy G, Vemuganti GK. Changing trends in ocular cysticercosis over two decades: an analysis of 118 surgically excised cysts. Indian J Med Microbiol. 2007 Jul; 25(3):214-9.

28. Prasad S, Jaiswal AK, Kumar D. Orbital cysticercosis- varied presentation and its management with Albendazole. AIOC 2008 proceedings: 422-23.

29. Lombardo J Subretinal cysticercosis. Optom Vis Sci. 2001 Apr;78(4):188-94.

30. Das et al. Neuro and intraocular cysticercosis: a clinic-pathological case report. Eye and Brain 2010:2, 39-42.

31. Chaudhry IA, Shamsi FA, Arat YO, Riley FC. Orbital pseudotumor: distinct diagnostic features and management. Middle East Afr J Ophthalmol. 2008 Jan;15(1):17-27. doi: 10.4103/0974-9233.53370.

32. Dubey RB, Tara N, Sisodiya KN. Computerised Tomographic evaluation of orbital diseases. Ind $\mathrm{J}$ Radiol Imag 2003; 13:261-70.

33. Bianciotto C, Demirci H, Shields CL, Eagle RC Jr, Shields JA. Metastatic tumors to the eyelid: report of 20 cases and review of the literature. Arch Ophthalmol. 2009 Aug; 127 (8): 999-1005. doi: 10.1001/ archophthalmol. 2009.120.

34. Betharia SM, Sharma V, Pushker N. Ultrasound findings in orbital hydatid cysts. Am J Ophthalmol. 2003 Apr; 135(4):568-70.

\section{How to cite this article?}

Netam SBS, Jain V, Singh R, Sanjay Kumar, Dutt V. Real time B-Scan evaluation of Posterior chamber \& extraocular pathologies of Eye \& Orbit. Int J Med Res Rev 2015;3(9):925-933. doi: 10.17511/ijmrr.2015.i9.173. 